\title{
Numerical comparison of cruciform weld and butt weld simulation and a study of fracture mechanics on two types of welds
}

\author{
Malika Tirenifi \\ University of Sidi Belabbes, LMSR Laboratory, 22000, Sidi Belabbes, Algeria \\ ternifi.malika@yahoo.fr, bttp://orcid.org/0000-0001-2345-6789 \\ Bahri Ould Chikh \\ University of Mascara, LSTE Laboratory, 29000, Mascara, Algeria. \\ b.ouldchikh@univ-mascara.dฆ,bttp:/ /orcid.org/0000-0002-2345-6790 \\ Benattou Bouchouicha, Ahmed Bensari \\ University of Sidi Belabbes, LMSR Laboratory, 22000, Sidi Belabbes, Algeria \\ benattou_b@yahoo.fr,bttp://orcid.org/0000-0003-2345-6791 \\ abmed.bensari@yahoo.com, bttp://orcid.org/0000-0001-2345-6792
}

\begin{abstract}
The modeling of the welding is desirable to guess the deformation of the components during manufacture, the position and the magnitude of maximum residual stresses and to envisage metallurgical effects in specific zones. The welding are problems of complex modeling requiring the thermal and structural solutions. This has to lead to the development of several software packages and codes for simulation by finite elements. The welding condition, the properties of the structure and their interactions have significant influences on the thermal and structural responses (temperature history, distortion, and residual stress) in welded structures. This paper presents a finite element procedure for the prediction of welding-induced residual stresses and distortions. Comparison is made with tow numerical example. The first example is a butt welded joint of two plates, while the second is a Cruciform welded joint of two plates with four passes. Moreover, a comparison between the Cruciform weld and the butt-weld which we can obtain the parameters of the linear fracture mechanics; stress intensity factor $\mathrm{K}$ and energy release rate $\mathrm{G}$.
\end{abstract}

KeYwORDS. Cruciform Weld; Butt Weld; Residual Stress; Energy Release Rate; Stress Intensity Factor.

\section{OPEN@ACCESS}

Citation: Tirenifi M., Ould Chikh E.B, Bouchouicha B., Bensari, A., Numerical comparison of cruciform weld and butt weld simulation and a study of fracture mechanics on two types of welds , Frattura ed Integrità Strutturale, 48 (2019) 357-369.

Received: 13.11 .2018

Accepted: 23.02.2019

Published: 01.04.2019

Copyright: (C) 2019 This is an open access article under the terms of the CC-BY 4.0, which permits unrestricted use, distribution, and reproduction in any medium, provided the original author and source are credited. 


\section{INTRODUCTION}

$\mathrm{T}$

he processes of welding induce modifications of microstructure, constraints, and deformations residual, which it is as much difficult to control. High residual stresses combined with the presence of hard phases can lead, with the embrittlement of the joint or, the distortions induced by a welding can induce misalignments of the parts making impossible the realization of a sequence of welding. The numerical simulation of the processes of welding very often appears as a means of privileged access to the sizes, which characterize them. Thus, the numerical simulation of welding is greater interest when it is a question of studying the mechanical resistance of a welded joint or to check the feasibility of a sequence of welding. The resistance of the welded joints does not depend only on the properties of the base metal and the filler metal employed, but also of the presence of geometrical defects of surface or internal defects (blowholes, lacks of penetration). Numerical modeling supports more and more in practice as respects design. The use of the powerful computers and the effective software can provide the valid results, which are used to increase reliability in the structural design [1-6]. The complex mathematical procedures take account of physical and geometrical non-linearities of the structure [7]. An important tool for mathematical modeling is in particular the finite element method [8].

The analysis of the constraints in the welding also had the considerable attention in the past. In [9], he was defined the stress intensity factor of the joint welded for typical structures, inter alia for a fillet weld. Lazzarin [10] discuss derivation of the stress intensity factor for the welded joints, they described distributions of the constraints in the vicinity of the edges of the welding. An exact solution on the analysis of the constraints of the fillet welds was described by Dawei [11].

To study the distribution of the temperature, a research was made by Guedes [12], he carried out an experimental study and numerical with respect to the fillet weld. Eight points were selected for measurements with three distances 15, 25 and 35 $\mathrm{mm}$, starting from the line of fusion; the eight points were selected on each side of the upper surface of the plates. He traced the longitudinal distribution of residual stress in the plate. He was observed an increase in the residual stresses abruptly equal to the yield stress close to the welding, and the longitudinal residual stresses decrease abruptly starting from the welding and become compressive in the areas beside the welding. There are very small compressive forces in the transverse edges of the plate.

According to the finite element calculations of Kenno and Park [13,14], the distributions are similar while they observed that the thinner plate has slightly smaller tensile stress and slightly bigger compressive stress. The measurement of residual stress in welded plates requires costly equipment and qualified technicians. Thus, many researchers use an idealized model to represent the residual stress distributed in a plate instead [15, 16, 17], Applying the idealized model in the studied plate. In thermal analysis, the heat input during the welding process was applied on the specimen using the moving volumetric heat flux in the numerical model. In the investigation that was developed by Goldak [18], for the T-joint weld, welding was performed via single-side welding with an angle $\theta=45^{\circ}$. The front and rear density distributions of the volumetric heat flux for the T-joint welding were governed by Eqs. (1)-(2), respectively.

$$
\begin{aligned}
& q_{f}(x, y, z)=\frac{6 \cdot \sqrt{3} \cdot f_{f} \cdot \eta \cdot Q}{a_{f} \cdot b \cdot c \cdot \pi \sqrt{\pi}} \exp \left(-\frac{3 X^{2}}{a_{f}^{2}}-\frac{3 Y^{2}}{b^{2}}-\frac{3 Z^{2}}{c^{2}}\right) \\
& q_{r}(x, y, z)=\frac{6 \cdot \sqrt{3} \cdot f_{r} \cdot \eta \cdot Q}{a_{r} \cdot b \cdot c \cdot \pi \sqrt{\pi}} \exp \left(-\frac{3 X^{2}}{a_{r}^{2}}-\frac{3 Y^{2}}{b^{2}}-\frac{3 Z^{2}}{c^{2}}\right)
\end{aligned}
$$

where $X=\left(x-x_{0}-v t\right), Y=\left(y-y_{0}\right) \cos \theta+\left(z-z_{0}\right) \sin \theta$ and $Z=-\left(y-y_{0}\right) \sin \theta+\left(z-z_{0}\right) \cos \theta, \quad(x 0, y 0, z 0)$ is the position of the point where the torch is aimed in the $(x, y, z)$ coordinate system, $\mathrm{Q}$ is the power input, $\eta$ represents the welding efficiency, where 0.85 is employed in the study of Kemppi [19], $\nu$ is welding velocity, $t$ is the transient time, and the parameters $a_{f}, a_{r}, b$ and $c$ refer to the geometry of the heat source for the welding being modeled. The $\mathrm{f}_{\mathrm{f}}$ and $\mathrm{f}_{\mathrm{r}}$, represent the front and rear heat apportionment of heat flux, where $f_{f}=2 a_{f} /\left(a_{f}+a_{r}\right)$ and $f_{r}=2 a_{r} /\left(a_{f}+a_{r}\right)$ are assumed by Estefen [20], respectively.

Furthermore, an experimentally validated numerical model was created by Hibbit [21], to investigate the residual stresses and the distortions in a T-joint welding using Abaqus, the differences between the numerical and experimental results are acceptable. In the fusion zone and its adjacent region, the numerical simulation of longitudinal residual stress shows good agreement with the experimental measurements. The disagreement between the numerical simulation and experimental 
measurement of transverse residual stress can be observed in some locations. The manufacturing residual stress possibly influenced the experimental results at some points. When the distance to the weld line increases, the welding effect on the final residual stress is small. The manufacturing stress will then have more influence on final stress field.

Weld joint configuration actually refers to more than just the joint geometry. Besides the shape or configuration of individual weld joints, it includes the location or placement of joints within the structure, that is, the structural arrangement. Together, joint configuration and the number and placement of weld joints determines ease of manufacture, cost, and structural integrity, including robustness against weld-induced distortion.

The purpose of this article is to study the temperature distribution and the residual stresses generated during welding by a numerical simulation for two different types of chamfers X-Groove and V-Groove. Moreover, this article was enriched by a numerical study to identify the $K$ and $G$ parameters for different crack lengths. Finally, we finish our work with a numerical study to describe the fracture behavior of the material for the three zones of the weld. The material chosen for this study is low carbon steel SA-516 Gr 70, which is the material commonly used for the manufacture of pressure vessels.

The aim of this contribution is to investigate the influence of various welding sequence schemes on distributions and values of residual stresses and distortions of SA 516 Gr 70 steel. The cruciform joint and butt-joint plates are investigated using a transient thermo mechanical analysis performed by the finite element program, ABAQUS. Moreover, in this present study compares the stress intensity factor of cruciform and the butt welded joint, in order to determine the influence of the joint geometry on the fracture mechanics parameters.

\section{DESCRIPTION OF THE NUMERICAL MODEL}

\section{Material proprieties}

$\mathrm{I}$ $\mathrm{n}$ this study we have choose two specimens welded by deferent types; cruciform welded joint and butt welded joint. The material of the plates is no allowed steel SA 516 Gr.70, with temperature-dependent thermal and mechanical material properties adopted from [22]. Fig. 1 present the mechanical behavior of steel SA 516 Gr.70 as a function of the temperature. The material model (PLASTIC_KINEMATIC) has been introduced with the mechanical properties coming from ASME, Section-II, Materials Properties, Part-D.

\begin{tabular}{rccccccccccc}
\hline Element (\%) & $\mathrm{C}$ & $\mathrm{S}$ & $\mathrm{P}$ & $\mathrm{Si}$ & $\mathrm{Mn}$ & $\mathrm{Ni}$ & $\mathrm{Cr}$ & $\mathrm{Mo}$ & $\mathrm{Cu}$ & $\mathrm{Ti}$ & $\mathrm{V}$ \\
SA 516 Gr.70 & 0.16 & 0.005 & 0.013 & 0.44 & 1.45 & 0.08 & 0.07 & 0.008 & 0.038 & 0.004 & 0.1 \\
\hline
\end{tabular}

Table 1: Chemical compositions.

\begin{tabular}{|c|c|c|c|c|c|c|c|c|c|}
\hline \multirow[b]{2}{*}{ Material } & \multicolumn{7}{|c|}{ Mechanical properties } & \multicolumn{2}{|c|}{ Thermal Properties } \\
\hline & $\begin{array}{l}\text { Yield } \\
\text { Strength } \\
\text { (MPa) }\end{array}$ & $\begin{array}{l}\text { Tensile } \\
\text { Strength } \\
\text { (MPa) }\end{array}$ & $\begin{array}{c}\text { Elongation } \\
\text { at Break } \\
(\%)\end{array}$ & $\begin{array}{l}\text { Modulus } \\
\text { of } \\
\text { Elasticity } \\
(\mathrm{GPa})\end{array}$ & $\begin{array}{c}\text { Poisson's } \\
\text { Ratio }\end{array}$ & $\begin{array}{c}\text { Bulk } \\
\text { Modulus } \\
(\mathrm{GPa})\end{array}$ & $\begin{array}{c}\text { Shear } \\
\text { Modulus } \\
\text { (GPa) }\end{array}$ & $\begin{array}{l}\text { Specific } \\
\text { Heat } \\
\text { Capacity } \\
\left(\mathrm{J} / \mathrm{g}^{\circ}{ }^{\circ} \mathrm{C}\right)\end{array}$ & $\begin{array}{l}\text { Thermal } \\
\text { Conductivity } \\
(\mathrm{W} / \mathrm{m}-\mathrm{K})\end{array}$ \\
\hline SA 516 Gr.70 & 355 & $485-620$ & 21 & 220 & 0.3 & 160 & 80 & 0.44 & 36.3 \\
\hline
\end{tabular}

Table 2: Mechanical properties and thermal properties at room temperature [23].

\section{NUMERICAL MODELING OF THE WELDING SIMULATION}

I $\mathrm{n}$ the form of an Abaqus/CAE Plug-In, that provides an easy-to-use graphical user interface to setup cross sectional (2-dimensional and axisymmetric) welding simulations from within Abaqus/CAE. The 2-D assumption where only a (planar or axisymmetric) 2-D cross section of the welded geometry is modeled is appropriate when the heat flow in the welding direction is minimal (such as when the welding speed is high).

The AWI is setup assuming the following methodology for performing a $2 \mathrm{D}$ welding simulation [24]:

1.The weld torch is simulated by applying a prescribed temperature (of magnitude higher than the melting temperature) at the boundary between the beads involved in the current weld pass and the neighboring region. 
2. The beads associated with the current pass and subsequent passes (i.e., beads yet to be deposited) are not present in the model during the weld torch application step for that pass. Beads for a pass are activated through the "model change" capability in a separate step just prior to the start of the cool down step for that pass.

3. The torch application and cool down are both analyzed through transient heat transfer steps. An optional "reset temperature" step that ramps the whole model to a constant temperature prior to the next pass is performed in a steadystate heat transfer step.

4. Temperature sensors defined at or near the user-defined depth are utilized to turn off energy input (and proceed to the cool down step) within the torch application step. Similarly, sensors are used to control the cool down process by monitoring the temperatures at the weld bead free surfaces of the already deposited weld bead.

5. Weld beads are always active during the stress analysis. However, to ensure the yet to be deposited beads do not influence the deformation, these un-deposited beads have nodal temperatures near the melting temperature as specified by the initial conditions. This leads to very soft or compliant mechanical material properties. Having all beads present from the start of the analysis allows for the beads to move with the deformation in the weld zone while not affecting the overall response until they are "active" or deposited. This is necessary for large deformation problems in welding simulations. In order to ensure a totally strain-free (including zero elastic strains) "activation", beads corresponding to a particular pass are removed and re-introduced just prior to the cool down step for that pass.
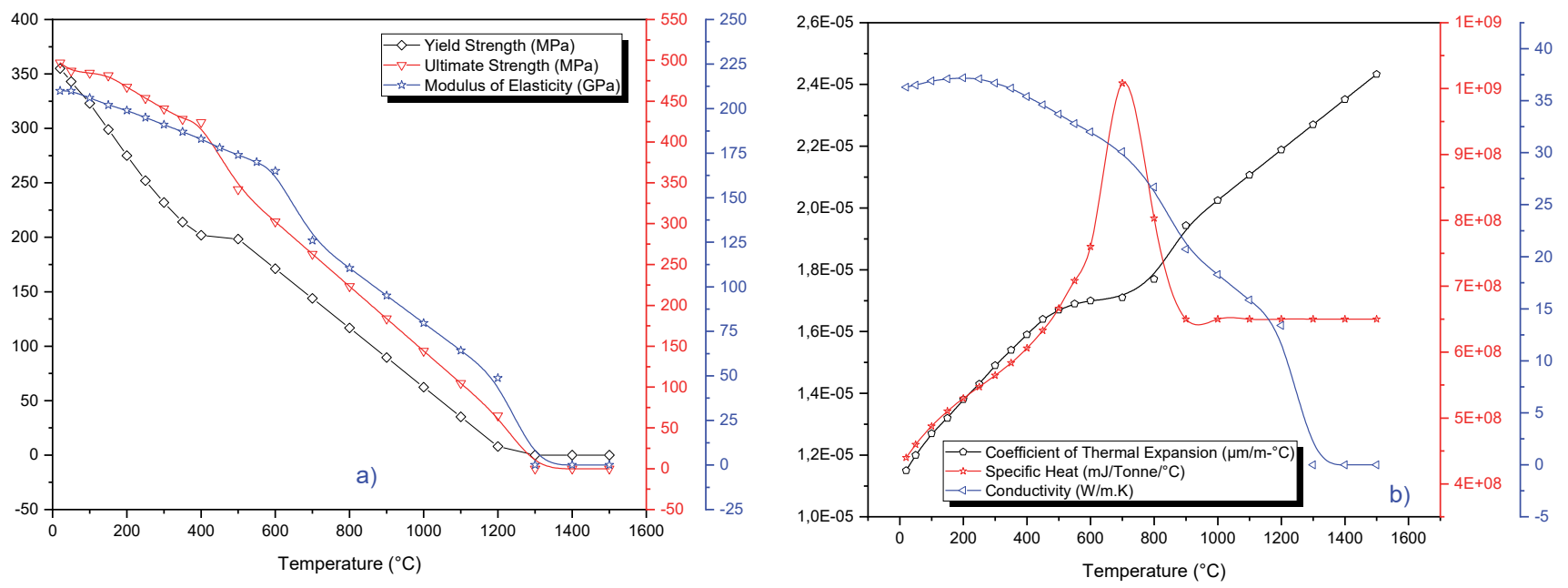

Figure 1: The variation of properties as a function with temperature. (a) Mechanical properties and (b) Thermal properties [23].

We proceeded to a modeling of the plates with welded by quadrilateral elements of transfer of heat, DC2D8 with 8 nodes. In Abaqus/Standard a sequential thermal-stress analysis is performed with two-dimensional, 8-node heat transfer elements, DC2D8, used for the heat transfer analysis and the corresponding 8-node plane strain continuum elements, CPS8R, used for the stress analysis. A generalized model of plane stress was employed for the mechanical analysis with quadrilateral elements, CPS8R with 8 nodes. The models are represented by the Figs. 2a-2b, respectively

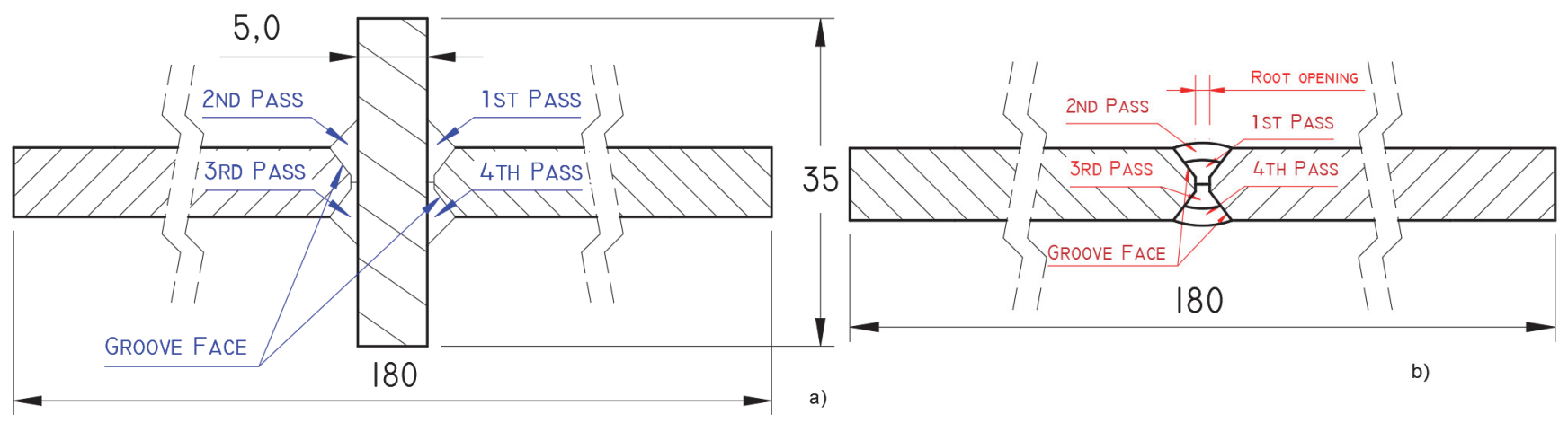

Figure 2: a) Cruciform welded joint, b) Butt welded joint. 
The structural model used a FORTRAN subroutine to cap the torch temperature at $1500^{\circ} \mathrm{C}$ to avoid excessively large thermal strains. This model used three steps which mirror the thermal analysis but combine the 'Apply Torch' and 'Torch Hold' from the thermal model into a single step, and again, like the thermal model, it removes all the weld beads in the very first step. The FEM structural model had 18 steps for 4 weld beads where the initial first step removed all the weld beads prior to the simulation. The mesh (see Fig. 3) consists of 31124 elements and 31595 nodes for the cruciform welded joint, 23414 elements and 23817 nodes for the butt-welded joint, with a refinement in all the welding passes, the minimum element sizes used in these models are about $0.1 \mathrm{~mm}$.
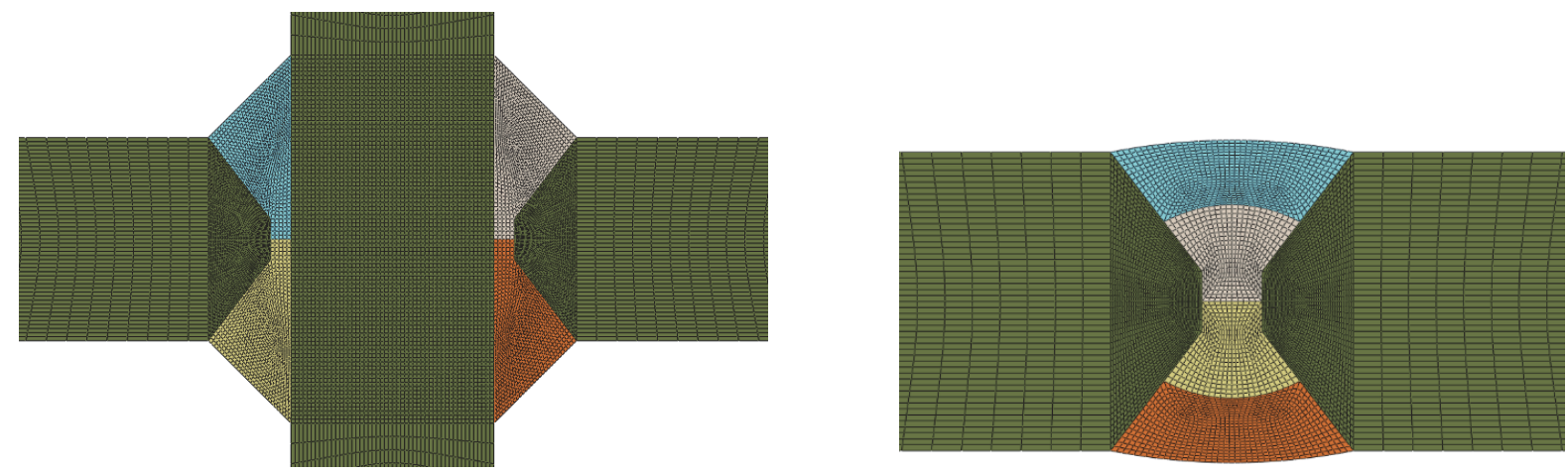

Figure 3: Mesh used for the modeling of cruciform weld and butt weld.

\section{RESULTS AND DISCUSSION}

$\checkmark$ he thermal and structural input decks were written out by the AWI plug-in. The structural input deck included kinematic hardening plastic material properties with the anneal temperature set at a temperature representative of the material melting temperature for both the base and weld materials. Calculation of the temperature field history during welding entails a transient thermal analysis. The thermal analysis is based on the heat conduction formulation using temperature-dependent thermo-physical properties [23] as shown in Fig. 1a and Fig. 1b moving heat source. The same finite element models used in the thermal analyses are employed in mechanical analyses, except for the element type and boundary conditions. The analyses are conducted using the temperature history calculated by the thermal analyses as the input information. Generally, in addition to the elastic, plastic, and thermal strain, the solid-state phase transformations give rise to two additional strains during welding.

For the thermal model, we can see a uniform heating and cooling around the passes and during the creation of them. Fig. 8a shows this uniformity during the heating and cooling for the two specimens. Method employed to order the heat flux in the thermal model for the models described in this document the limit was fixed at $1500^{\circ} \mathrm{C}$ [24].
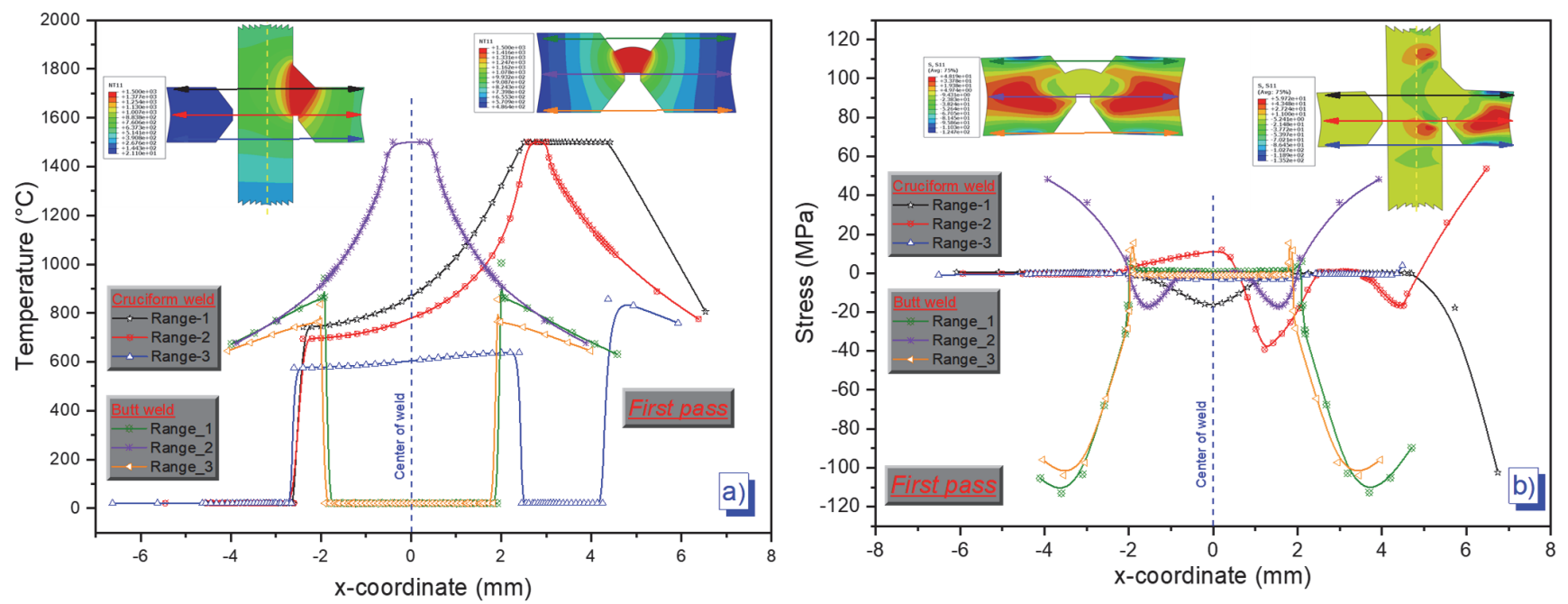

Figure 4: First pass, a) Comparison of temperature distribution-butt weld vs. cruciform weld, b) Comparison of residual stress distribution-butt weld vs. cruciform weld. 
Fig. 4a shows temperature profiles in butt-welded plates and cruciform welded plates after the start of welding along the width of two plates (first pass). As may be seen from Fig. 4a, the obtained maximum temperature in the weld is $1500{ }^{\circ} \mathrm{C}$ for butt weld (first pass) and $900^{\circ} \mathrm{C}$ for cruciform weld (first pass), and the temperature profile has a typical parabolic shape in the weld bead.

Fig. $4 \mathrm{~b}$ present the residual stress fields obtained by the finite element methods on the fusion line of the welded plates. It can be seen that the residual stress fields for the welded plates are different. It shows the residual stress profile in the location width of two plates, it can be seen that the residual stresses obtained are different. Moreover, the residual stress measured in the center of the weld significantly deviates from the numerically calculated values for butt weld and cruciform weld. It is noticed that there are stresses of tension $(x= \pm 4 \mathrm{~mm}, 55 \mathrm{MPa}$, butt weld-first pass, range_2) and compression ( $\mathrm{x}= \pm 4 \mathrm{~mm}$, $110 \mathrm{MPa}$, butt weld-first pass, range_1 and range_3), for the cruciform weld, we have obtained stresses of tension $(\mathrm{x}=+6$ $\mathrm{mm}, 60 \mathrm{MPa}$, range-2) and stresses of compression $(\mathrm{x}=+6 \mathrm{~mm}, 100 \mathrm{MPa})$. The compressive stresses are produced at the point of the deposit of the welding.
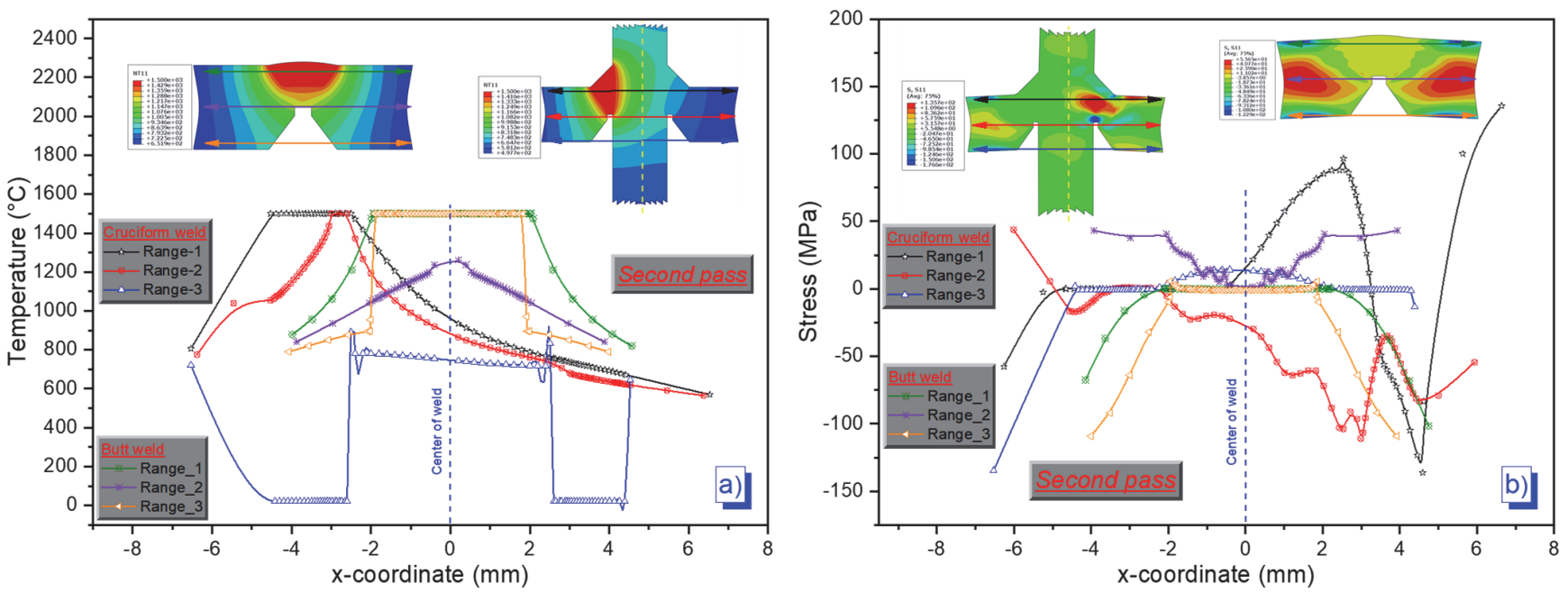

Figure 5: Second pass, a) Comparison of temperature distribution-butt weld vs. cruciform weld, b) Comparison of residual stress distribution-butt weld vs. cruciform weld.
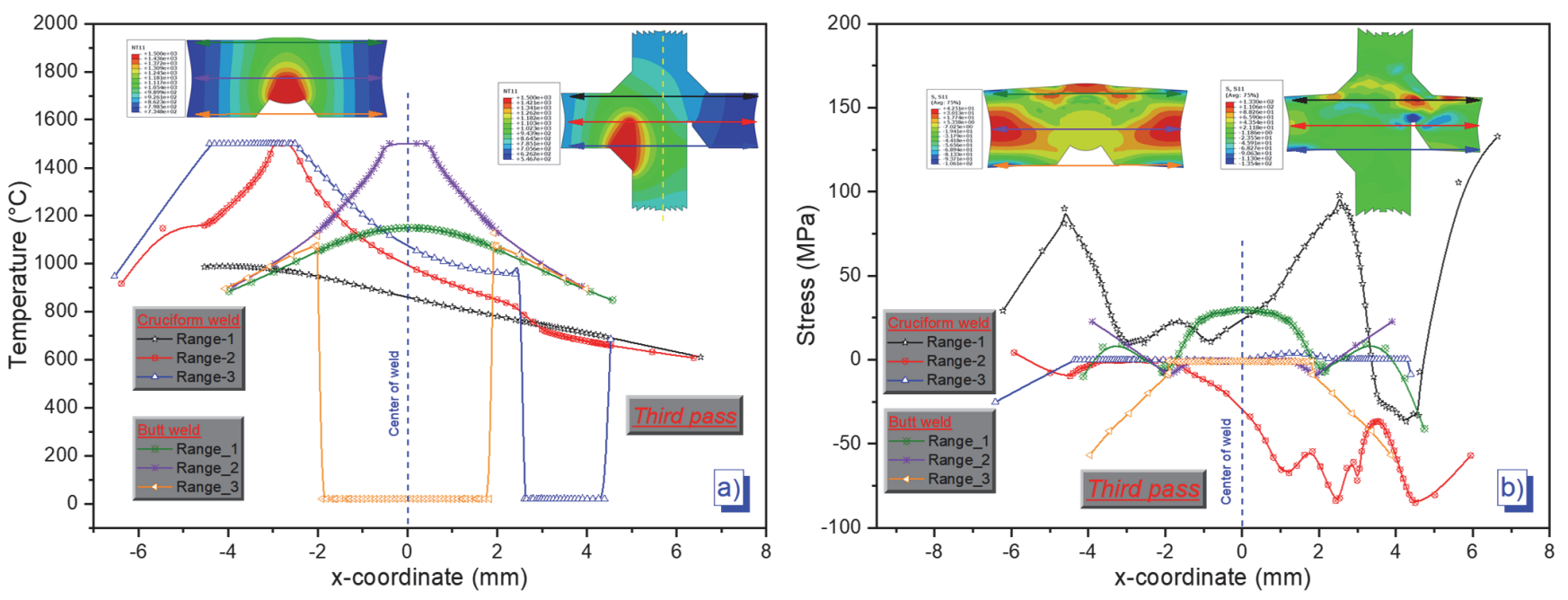

Figure 6: Third pass, a) Comparison of temperature distribution-butt weld vs. cruciform weld, b) Comparison of residual stress distribution-butt weld vs. cruciform weld.

Figs. 5 a shows temperature profiles along the location line in width of the plates. It can be seen that the solutions obtained by the numerical method. A comparison of the temperature history on the measurement locations obtained by the numerical method for cruciform welded plates and butt-welded plates, shows that their temperature history is nearly identical. The 
temperatures decrease when the distance between the measure points and the weld centerline increases. It is noted that the peak temperature in the butt weld is higher than the cruciform weld because of the effect of the geometry, which confirms that the higher temperatures are induced in the specimen with bigger stiffener.

Fig. $5 \mathrm{~b}$ plots the transversal residual stress distribution in the two plates. Significant high compressive stresses (130 MPa for Cruciform weld-second pass, range-1). It is observed that the transversal residual stresses increase sharply away from the center of weld. There are very small tensile stresses in the mid-span of the butt-welded plate (second pass).

The results show in Fig. 6b, that heat input has large effect on the maximum tensile and compressive residual stresses and on the location of the maximum values. It means that the size of the heat affected zone is increasing by increasing heat inputs, and the peak stress decreases on the interface of the molten and stiff materials. The maximum longitudinal residual stress varies between $-75 \mathrm{MPa}$ and $125 \mathrm{MPa}$, which can be considered as a significant influence depending on the heat input parameter. If the amount of the molten material increases, the maximum longitudinal stress decreases.
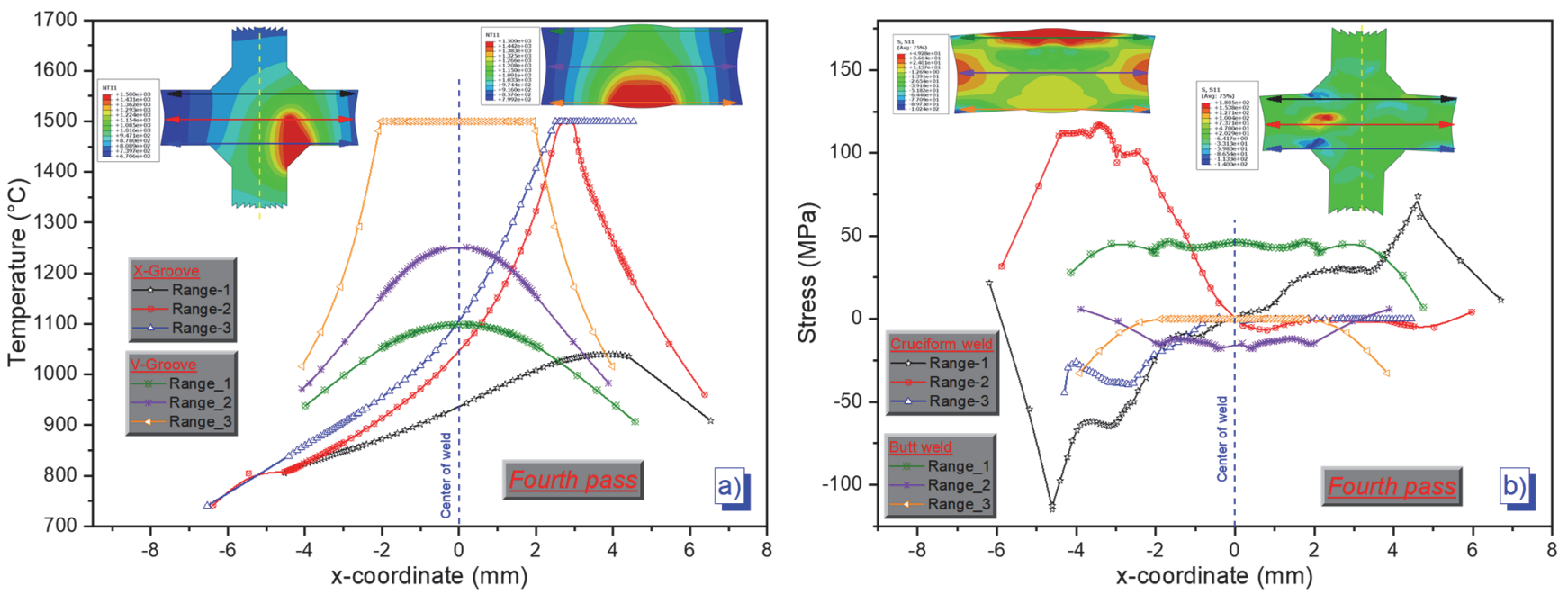

Figure 7: Fourth pass, a) Comparison of temperature distribution-butt weld vs. cruciform weld, b) Comparison of residual stress distribution-butt weld vs. cruciform weld.
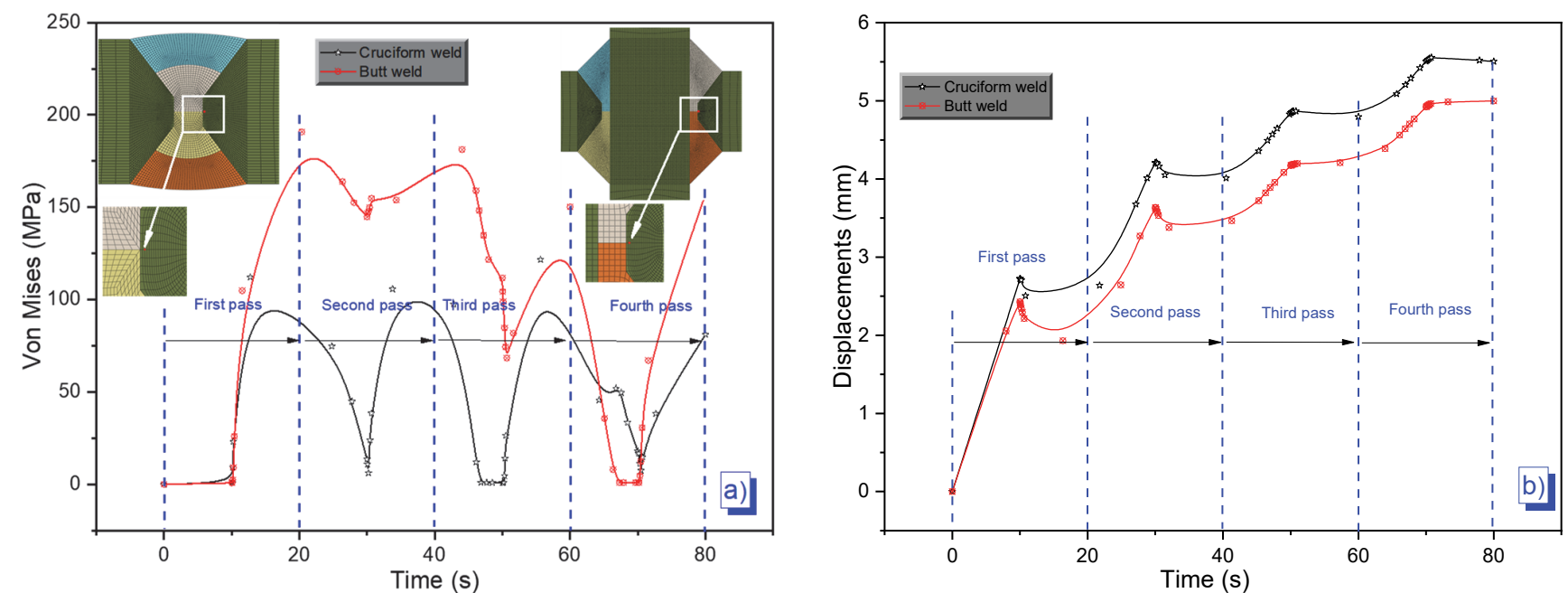

Figure 8: a) Von Mises stresses, b) Distortion of a node during the welding for the tow plates of weld.

The difference between the two models is in the consideration of the phase transformation (see Fig. 7a). The maximum temperature per each pass increases monotonously while the ambient temperature is assumed to be constant during welding $\left(21.1^{\circ} \mathrm{C}\right)$. It can be seen that the cooling rates are getting higher for the weld passes due to the effect of radiation.

Fig. $7 \mathrm{~b}$ plots the transversal residual stress distribution in the two plates for the fourth pass. Significant high tensile and compressive stresses (110 $\mathrm{MPa}$, range-1, $125 \mathrm{MPa}$, range-2, for Cruciform weld, respectively). It is observed that the 
transversal residual stresses increase sharply away from the center of weld. There are small compressive stresses $\sim 10 \mathrm{MPa}$, range_2 and tensile stresses $\sim 50 \mathrm{MPa}$, range_1 for the butt-welded plate.

Fig. $8 \mathrm{~b}$ shows the vertical displacements of a node during the welding for the tow plates of weld. The thicknesses of all plates are $5 \mathrm{~mm}$. The non-symmetric welding sequence results in asymmetry of the vertical displacement in the cruciform welded plate. The left side of the plate where the second welding operation completed has bigger deflections. The maximum displacement $(2.9 \mathrm{~mm})$ occurs in the right side of the cruciform welded plate (first pass) and is much bigger than the one in the left side ( $4.3 \mathrm{~mm}$, second pass) and is much bigger than the one in the left side ( $4.9 \mathrm{~mm}$, third pass). The maximum displacement is $5.29 \mathrm{~mm}$ occurs the four passes.
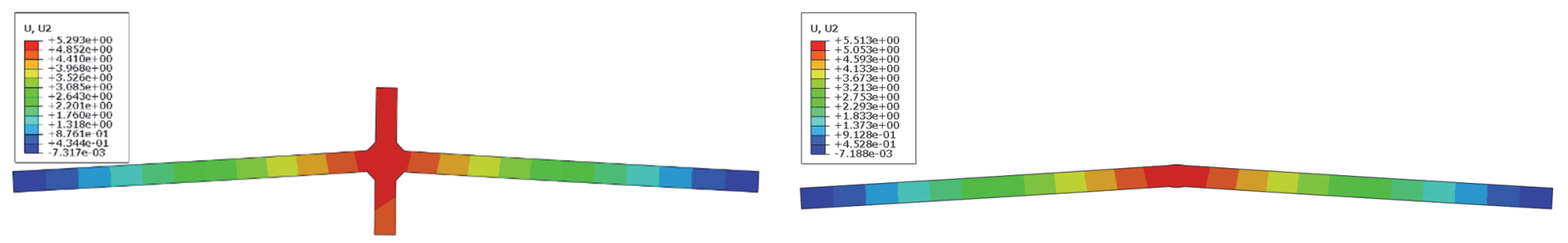

Figure 9: vertical displacement in the welded plates.

The vertical displacement of the welded plates is plotted in Fig. 9. The distribution behaves almost linearly from the weld to the transverse edges. Maximum displacement (5.29 $\mathrm{mm}$ for the cruciform weld, $5.51 \mathrm{~mm}$ for the butt weld) occurs in the corner of the end section in terms of the welding direction. It is also observed that the displacements on the two edges of the plate are not exactly equal. Consequently, minor differences appear between the angular distortions in two types of weld.

\section{EXTRACTION OF SIF AND G VALUES}

I n fracture mechanics, the Stress intensity Factor $K$ is frequently used to predict the stress state close to the crack tip. The stress may be caused by a remote load. It can be theoretically used to provide a criterion for failure of homogeneous elastic materials. The linear elastic material constitutive properties are defined by the Young's modulus $\mathrm{E}$ and Poisson's ratio $v$. The temperature-independent elastic modulus and Poisson's ratio are assumed to be $220 \mathrm{GPa}$ and 0.3 , respectively.

The factor K gathers with him only the influence of the dimension of the crack, the forces applied and the geometry of the cracked part. The success of the fracture mechanics comes from what the conditions at the end of the crack depend on only and single parameter.

In this study, we make a comparison between a cruciform welded joint and a butt-welded joint for 2D dimensions and 3D dimensions to see the differences parameters of linear fracture mechanics between the two configurations.

\section{Model 2D dimensions}

FE simulations are conducted by ABAQUS. The specimens having a thickness B of $5 \mathrm{~mm}$ with the length of $180 \mathrm{~mm}$, with various dimensions of the cracks 0.5,1.0,1.5,2.0 and $2.5 \mathrm{~mm}$ (see Fig. 10 and Fig. 11). Three different pressures 120,160 and $200 \mathrm{MPa}$ are applied on the right side of the tow specimens.
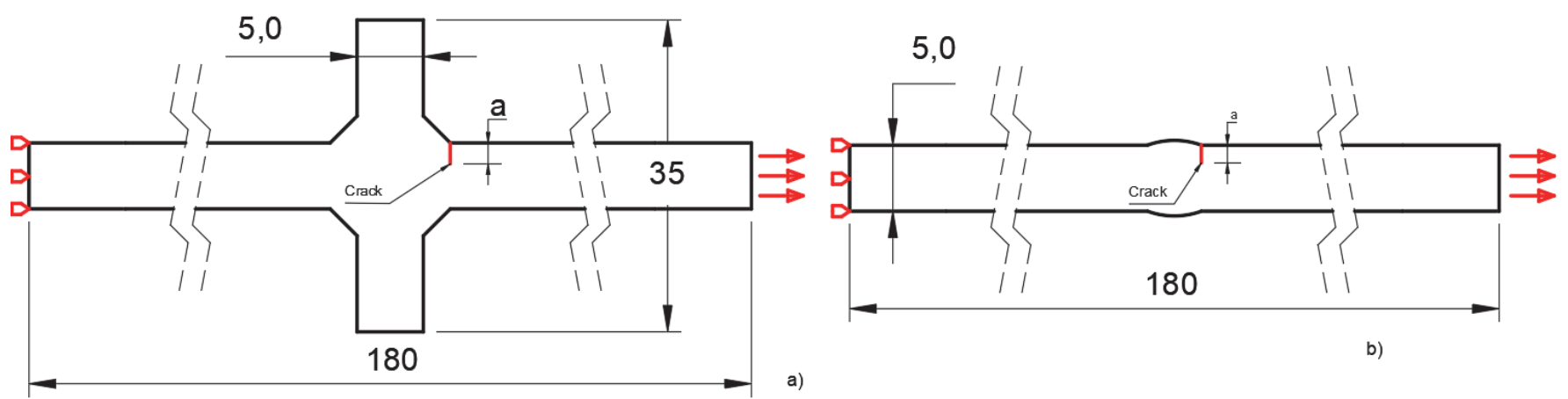

b)

Figure 10: The location of the crack examined for 2D dimensions, a) the cruciform weld toe, b) the butt weld toe. 

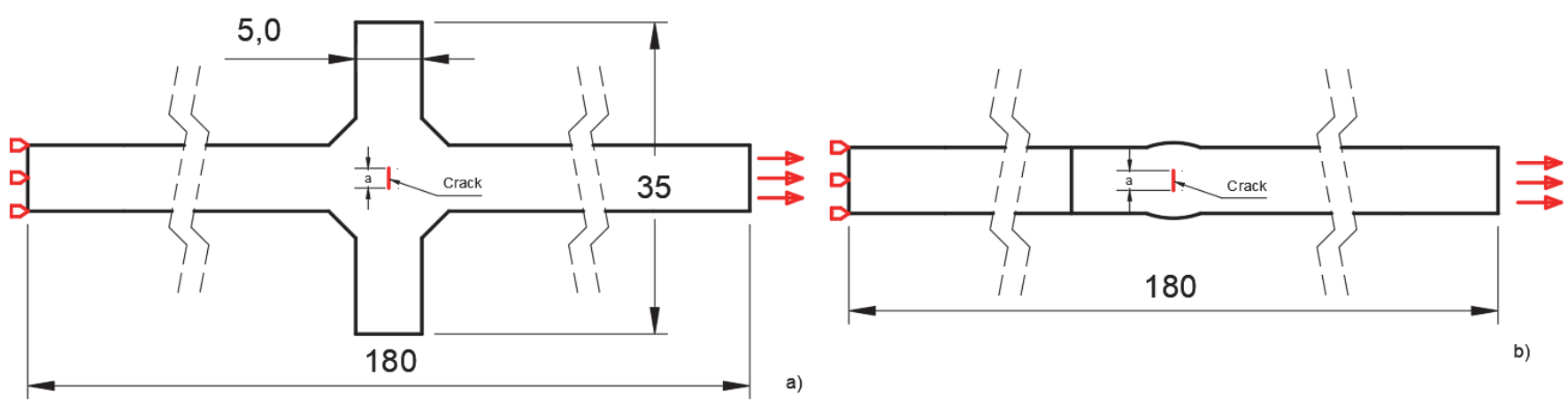

a)

b)

Figure 11: The location of the crack examined for 2D dimensions, a) the cruciform weld root, b) the butt weld root.

8-node biquadratic plane stress quadrilateral elements are used in 2D models as shown in Fig. 12. The total number of elements are 28861 and 23974 for cruciform and butt weld, respectively. Note that a 6-node quadratic plane stress triangle are used in the crack front and the element sizes in these models are about $0.125 \mathrm{~mm}$ around the crack front. $\mathrm{K}$ and $\mathrm{G}$ are computed based on the domain integral using 4 contours.
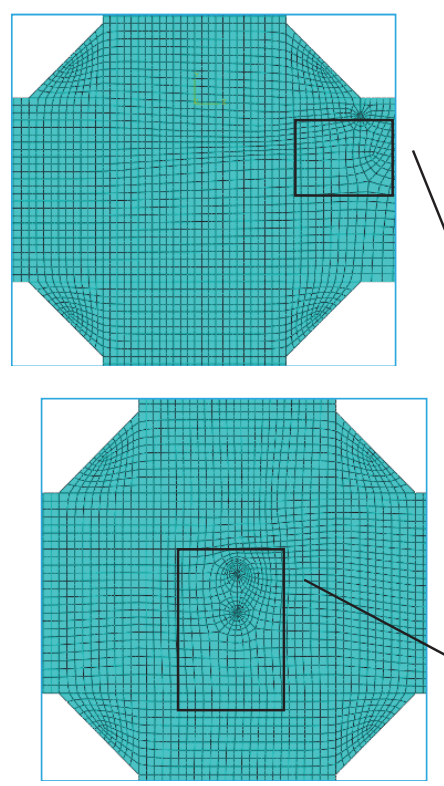
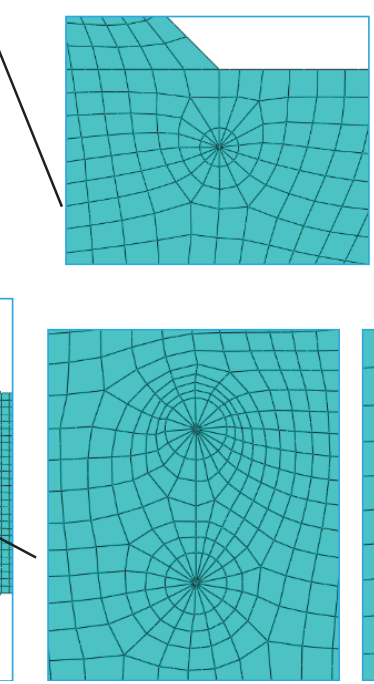
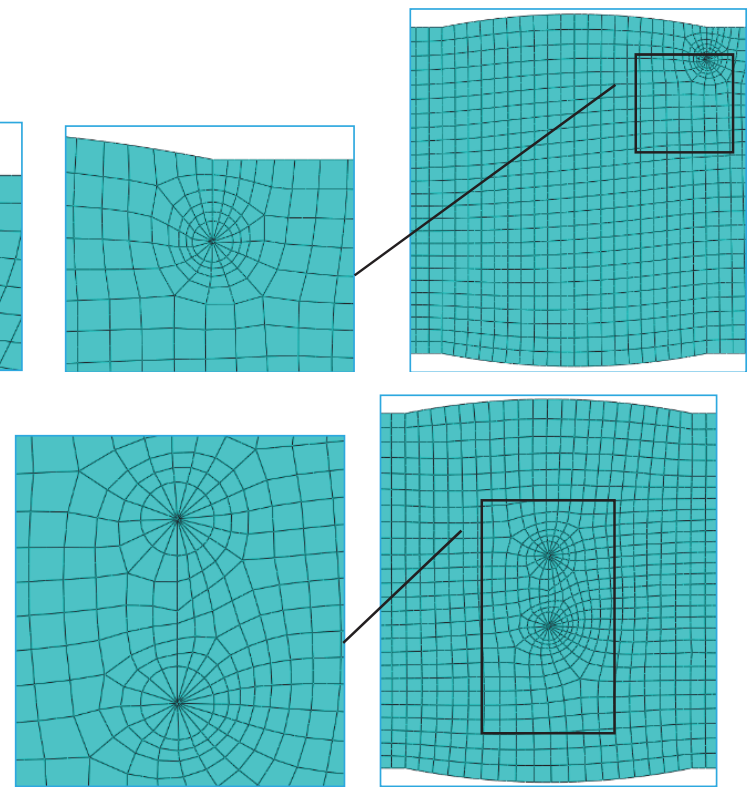

Figure 12: Mesh used for the FE simulations of cruciform weld and butt weld.

\section{NUMERICAL RESULTS AND DISCUSSION}

\section{Weld toe}

7 he results of the numerical study for the cruciform and butt-welded joints, with equal attachment and main plate thickness $B=5 \mathrm{~mm}$, are plotted in Fig. 13. This figure presents the results of $\mathrm{K}$ factor and $\mathrm{G}$ against the crack length $a$, with parabolic curves. Increasing of $a$, increase the value of $\mathrm{K}$ and $\mathrm{G}$. It can be seen that the effect of $a$ is most important on the values of $\mathrm{K}$ and $\mathrm{G}$. the effect of the $a$ on the stress intensity factor and the energy realize rate for cruciform welded joint is similar to that for the butt welded joint. It can be seen that the welding profile has no effect on the parameters of the fracture mechanics. The values of the stress intensity factor and $G$ for cruciform and butt-welded joint are almost similar. 

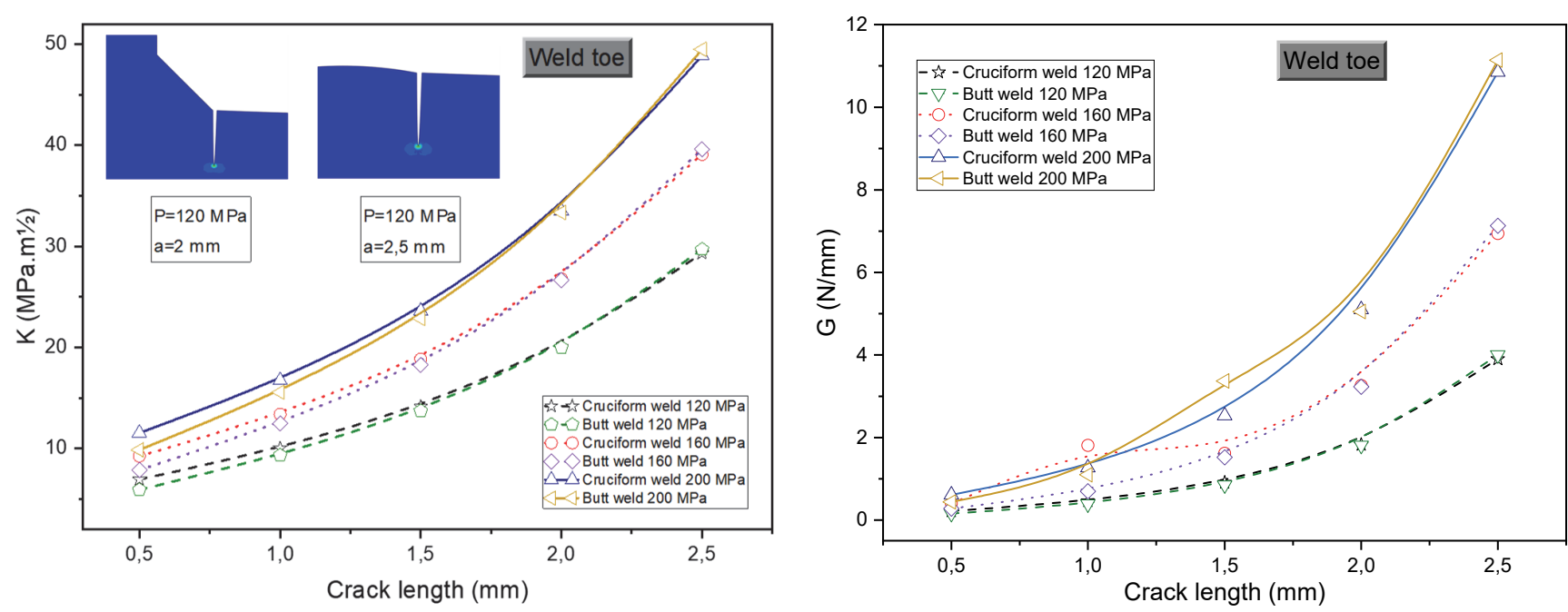

Figure 13: Numerical $\mathrm{K}$ and $\mathrm{G}$ values for cruciform and butt weld in which the crack is located in weld toe.

\section{Weld root}

The results were plotted in Fig. 14, as values of K and G versus $a$ length of crack. It can be seen that the effect of $a$ in the cruciform welded joint is less than that in the butt-welded joint. However, in this case, the welding profile has a significant effect on the parameters of the fracture mechanics. For all the different crack lengths and pressures, the butt-welded joint has the greater values of $\mathrm{K}$ and $\mathrm{G}$ than the cruciform welded joint.
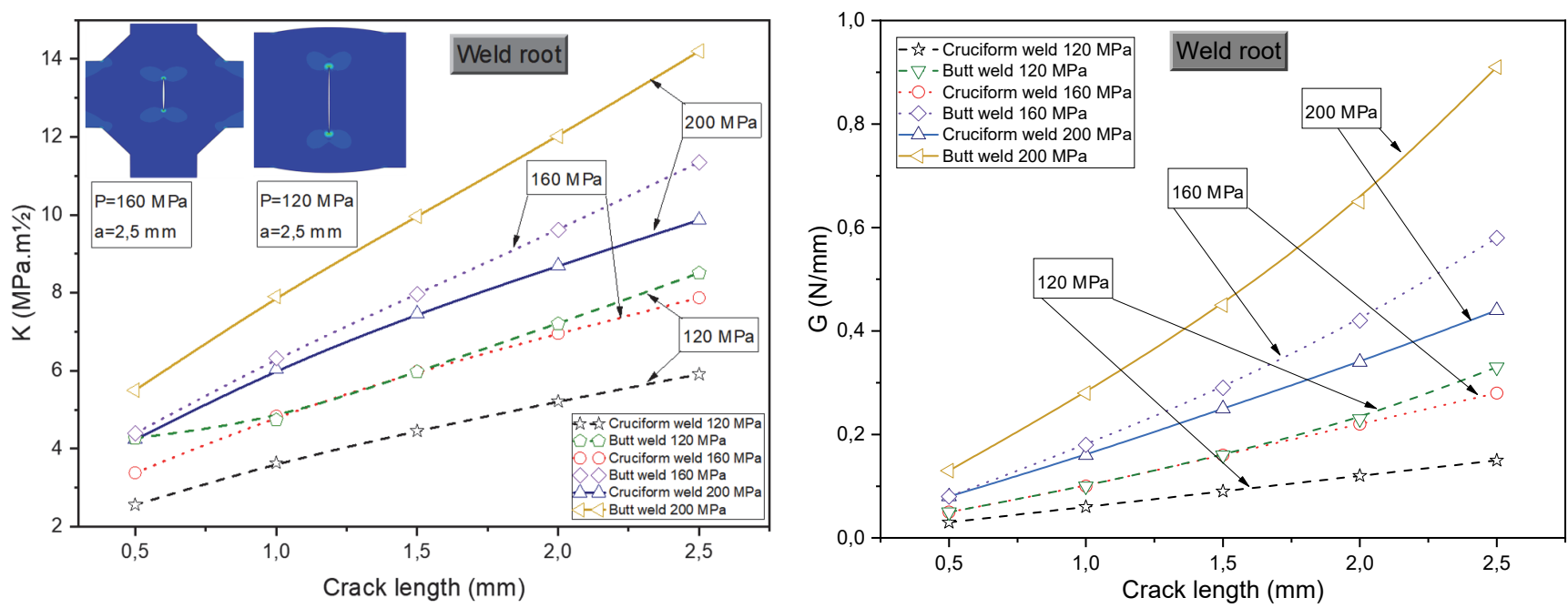

Figure 14: Numerical $\mathrm{K}$ and $\mathrm{G}$ values for cruciform and butt weld in which the crack is located in weld root.

As observed from Fig. 14, for the cruciform welded joint, $\mathrm{K}$ at the surface point also increases with an increase of $a$. When the crack length varies from 0.5 to $2.5 \mathrm{~mm}, \mathrm{~K}$ at the surface point increases by $130,97 \%, 132,71 \%$, and $132,83 \%$ at $P=120$, 160 , and $200 \mathrm{MPa}$, respectively. Moreover, for the butt-welded joint, $\mathrm{K}$ at the surface point also increases with an increase of $a$. When the crack length varies from 0.5 to $2.5 \mathrm{~mm}, \mathrm{~K}$ at the surface point increases by $99,25 \%, 158,27 \%$, and $158,04 \%$ at $P=120,160$, and $200 \mathrm{MPa}$, respectively.

Comparison of the results between cruciform and butt welded joint, such as the weld toe, has stress intensity factor and $G$ values higher than the stress intensity factor and $G$ values for the weld root crack.

\section{Model 3D dimensions}

In this section, a 3D model is analyzed by ABAQUS (see Fig. 15), One end of the main plate parallel to crack face is restrained and a uniform axial stress 120,160 and $200 \mathrm{MPa}$ is applied at the other end of the plate to provide the loading condition. The material employed in the analyses is SA 516 Gr 70 [23] with Young's modulus E and Poisson's ratio $v$ being $220 \mathrm{GPa}$ and 0.3 , respectively. 


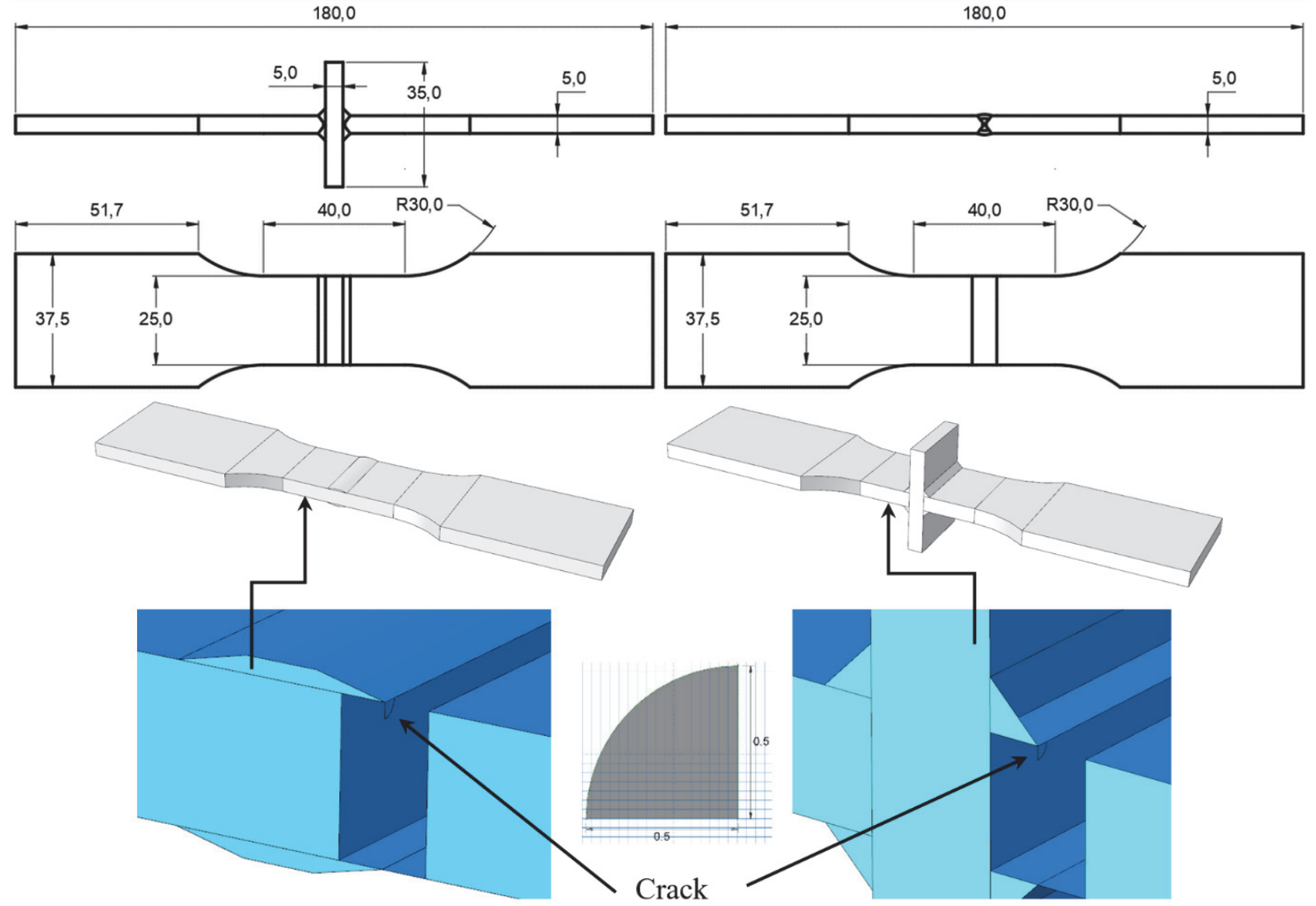

Figure 15: The location of the semi-circular crack for the cruciform welded joint and the butt welded joint examined for 3D dimensions.

The mesh of the two specimens is carried out using meshes linear C3D8R with eight nodes (see Fig. 16). The cruciform welded plate constitutes of 30150 elements and 35343 nodes, on the other hand, the butt-welded plate constitutes of 33100 elements and 37434 nodes. In the content of crack, it is particularly refined for modeling in local approach.

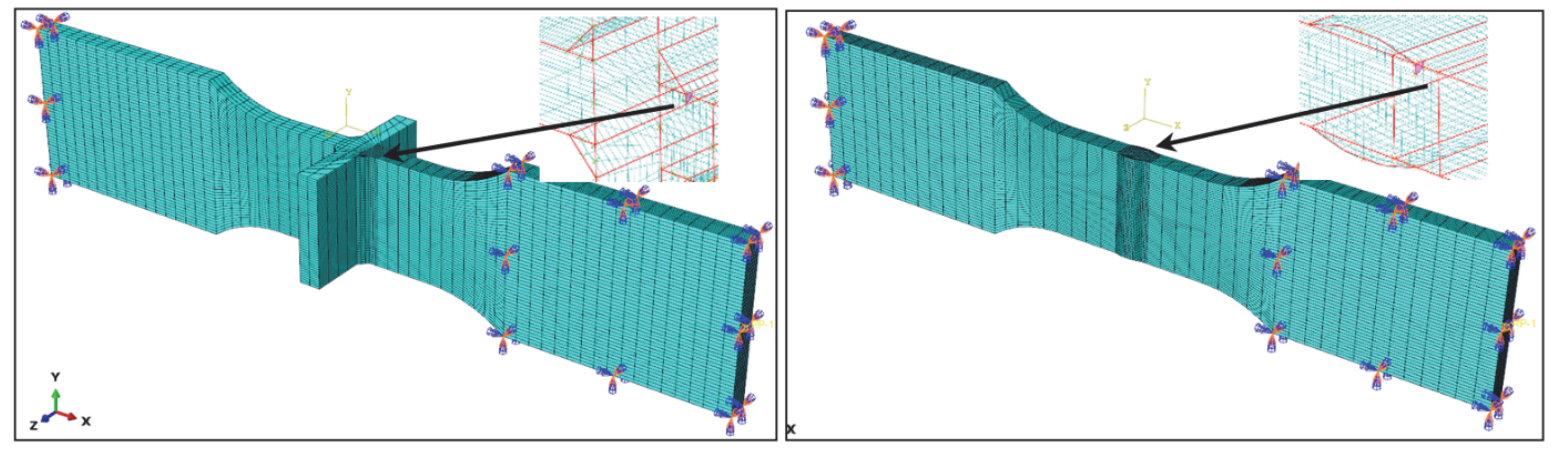

Figure 16: Mesh used for two specimens.

\section{RESULTS AND DISCUSSION}

$\mathrm{I}$ $\mathrm{n}$ this section, finite element calculations were performed by considering a linear-elastic material behavior. The Young's modulus and the Poisson's ratio were set equal to $\mathrm{E}=220 \mathrm{GPa}$ and $\nu=0.3$ (parameters of steel). Results achieved for the $\mathrm{K}$ and $\mathrm{G}$ evaluation are shown in Fig. $17 \mathrm{a}$ and $17 \mathrm{~b}$. It is seen that the $\mathrm{K}$ values and $\mathrm{G}$ for cruciform weld are greater than those calculated for butt weld, until $\mathrm{a}=1,5 \mathrm{~mm}$, the $\mathrm{K}$ values and $\mathrm{G}$ for cruciform weld are lesser than those calculated for butt weld and the difference between both values increases with increasing stress amplitude. 
As observed from Fig. 17, for the cruciform welded joint, $\mathrm{K}$ at the surface point also increases with an increase of $a$. When the crack length varies from 0.5 to $2.5 \mathrm{~mm}, \mathrm{~K}$ at the surface point increases by $35,49 \%, 37,45 \%$, and $37,53 \%$ at $\mathrm{P}=120$, 160 , and $200 \mathrm{MPa}$, respectively. Moreover, for the butt-welded joint, $\mathrm{K}$ at the surface point also increases with an increase of $a$. When the crack length varies from 0.5 to $2.5 \mathrm{~mm}, \mathrm{~K}$ at the surface point increases by 59,16\%, 59,30\%, and 59,30\% at $\mathrm{P}=120,160$, and $200 \mathrm{MPa}$, respectively.
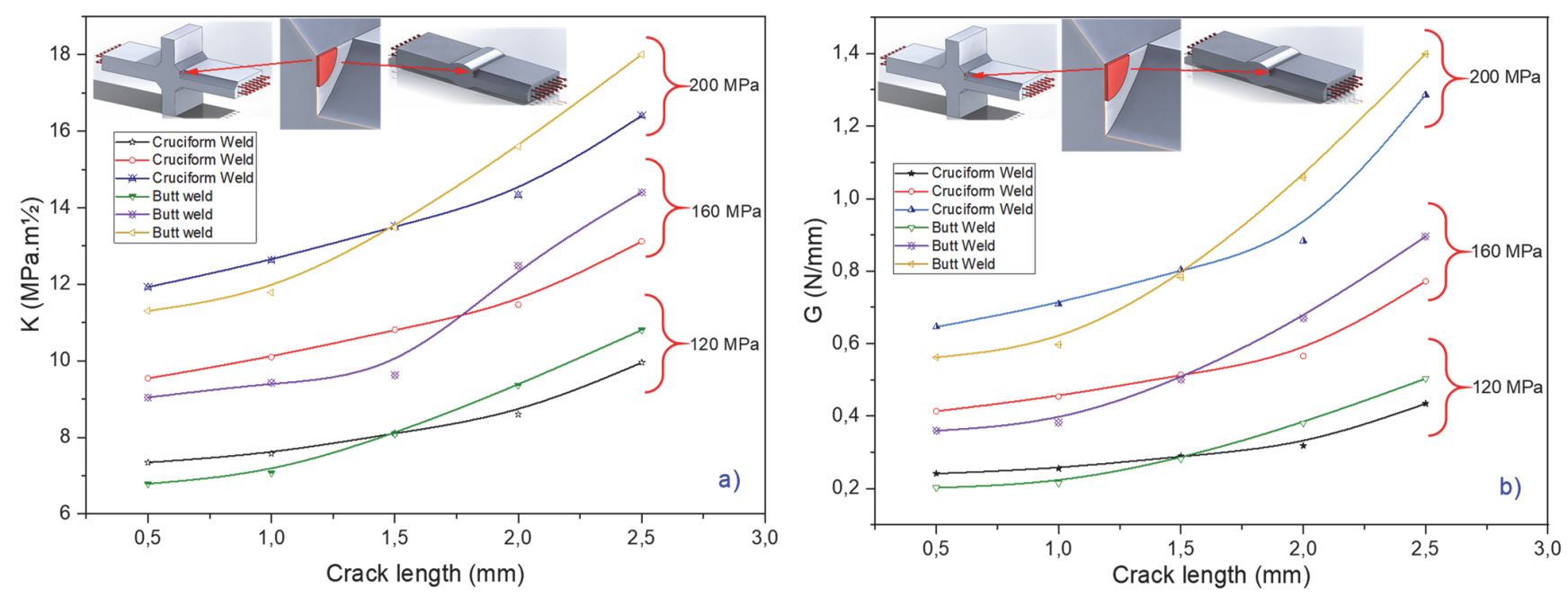

Figure 17: Numerical $\mathrm{K}$ and $\mathrm{G}$ values for cruciform weld and butt welds.

\section{CONCLUSION}

A detailed thermal and thermo-mechanical analysis procedure was applied to a butt joint and cruciform weld with four passes. The objective of this work is to access the importance of an accurate prediction of the weld induced residual stresses and distortion based on numerical simulations.

The welding simulation has shown that at the time of the deposition of the filler metal and during the heating and cooling of the assembled edges, compressive and tension stresses have been produced, this is due to the change in phases and the birth of the two welding zones, the fusion zone and the heat affected zone, the following conclusions can be illustrated:

- The obtained maximum temperature in the weld is $1500{ }^{\circ} \mathrm{C}$ for butt weld (first pass) and $900{ }^{\circ} \mathrm{C}$ for cruciform weld (first pass), and the temperature profile has a typical parabolic shape in the weld bead.

- There are stresses of tension and compression for all the passes in the both welded plates.

- Maximum displacement is $5.29 \mathrm{~mm}$ for the cruciform weld, $5.51 \mathrm{~mm}$ for the butt weld.

- We have used a numerical method of analysis, which can calculate $\mathrm{K}$ and $\mathrm{G}$ of a crack in a tow-dimensional and threedimensional model. For this part, the values of $\mathrm{K}$ and the energy release rate for the case when the mechanical efforts are applied with different lengths of the crack

- The values of the stress intensity factor and $G$ for cruciform and butt-welded joint are almost similar in which the crack is located in the weld toe.

- Comparison of the results between cruciform and butt welded joint, such as the weld toe, has stress intensity factor and $G$ values higher than the stress intensity factor and $G$ values for the weld root crack.

- It notices that $\mathrm{K}$ and $\mathrm{G}$ increase when the length of the crack and the load applied increase.

As future work, the SIF and G will be calculated with the consideration of the residual stresses, furthermore, a special research will be established for the extraction of SIF and G during welding. Finally, further application of the numerical simulation of welding will be extended to 3D models. 


\section{REFERENCES}

[1] Janas, P, Krejsa, M, Krejsa, V. (2009). Structural reliability assessment using a direct determined probabilistic calculation. structural and environmental engineering computing, pp. 72. DOI: 10.4203/ccp.91.72.

[2] Janas, P., Krejsa, M., Krejsa, V., Bris, R. (2015). Structural reliability assessment using direct optimized probabilistic calculation with respect to the statistical dependence of input variables. Safety and Reliability of Complex Engineered Systems. pp. 4125-4132. DOI:10.1201/b19094-540.

[3] Kralik, J., Kralik, Jr J. (2014). Failure probability of NPP Communication Bridge under the extreme loads. Applied Mechanics and Materials, pp. 81-85. DOI: 10.4028/www.scientific.net/AMM.617.81.

[4] Krejsa, M., Janas, P., Yilmaz, I., Marschalko, M., Bouchal, T. (2013). The use of the direct optimized probabilistic calculation method in design of bolt reinforcement for underground and mining workings. The Scientific World Journal, pp. 1-13. DOI:10.1155/2013/267593.

[5] Krejsa, M., Janas, P., Krejsa, V., Kala, Z., Seitl, S. (2016). DOProC-based reliability assessment of steel structures exposed to fatigue. Perspectives in Science, 7. pp. 228-235. DOI:10.1016/ j.pisc.2015.11.037.

[6] Krejsa, M., Kralik, J. (2015). Probabilistic computational methods in structural failure analysis. Journal of Multiscale Modelling, 6(2). pp. 1-5. DOI:10.1142/S1756973715500067.

[7] Koubova, L., Janas, P., Krejsa, M. (2016). Load carrying capacity of steel arch reinforcement taking into account the geometrical and physical nonlinearity. Applied Mechanics and Materials, pp. 709-716. DOI: 10.4028/www.scientific.net/AMM.821.709.

[8] Zienkiewicz, O.C., Taylor, R.L., Fox, D.D. (2013). The Finite Element Method for Solid and Structural Mechanics. 7th. Butterworth-Heinemann, Oxford. DOI:10.1016/B978-1-85617-634-7.00025-9.

[9] Hobbacher, A. (1993). Stress intensity factors of welded joints. Engineering Fracture Mechanics, 46(2). pp. 173-182. DOI: 10.1016/0013-7944(93)90278-Z

[10] Lazzarin, P., Tovo, R. (1998) A notch intensity factor approach to the stress analysis of welds. Fatigue \& Fracture of Engineering Materials \& Structures, 21(9). pp. 1089-1103. DOI:10.1046/j. 1460-2695.1998.00097.x.

[11] Dawei, X. (1995). An exact solution on the stress analysis of fillet welds. Applied Mathematics and Mechanics, 16(11), pp. 1019-1024. DOI: 10.1007/BF02484368

[12] Guedes Soares, C., Bai-Qiao, C. (2016). Effects of plate configurations on the weld induced deformations and strength of fillet-welded plates, Marine Structures, 50. Pp. 243-259. DOI: 10.1016/j.marstruc.2016.09.004

[13] Kenno, S.Y., Das, S., Kennedy, J.B., Rogge, R.B., Gharghouri, M. (2010). Residual stress distributions in ship hull specimens. Marine Structure, 23. pp. 263-273. DOI: 10.1016/j.marstruc.2010.07.001.

[14] Park, J.U., An, G., Woo, W.C., Choi, J.H., Ma, N. (2014). Residual stress measurement in an extra thick multi-pass weld using initial stress integrated inherent strain method. Marine Structure, 39. pp. 424-437. DOI: 10.1016/j.marstruc.2014.10.002.

[15] Gannon, L., Liu, Y., Pegg, N., Smith, M.J. (2012). Effect of welding-induced residual stress and distortion on ship hull girder ultimate strength. Marine Structure, 28. pp: 25-49. DOI: 10.1016/j.marstruc.2012.03.004.

[16] Gannon, L., Liu, Y., Pegg, N., Smith, M.J. (2010). Effect of welding sequence on residual stress and distortion in flatbar stiffened plates. Marine Structure, 23. pp. 385-404. DOI: 10.1016/j.marstruc.2010.05.002.

[17] Cui, W., Mansour, A.E. (1998). Effects of welding distortions and residual stresses on the ultimate strength of long rectangular plates under uniaxial compression. Marine Structure, 11. pp. 251-269. DOI: 10.1016/S0951-8339(98)00012-4.

[18] Goldak, J. (1984). A new finite element model for welding heat source. Metallurgical and Materials Transactions B, 15(2). pp: 299-305. DOI: 10.1007/BF02667333.

[19] KEMPPI. (2013). Product introduction of KEMPPI Pro Evaluation 3200, 4200 and 5200. Lahti, Finland: Kemppi Oy.

[20] Estefen, T.P., Estefen, S.F. (2012). Buckling propagation failure in semi-submersible platform columns. Marine Structure, 28(1). pp: 2-24. DOI: 10.1016/j.marstruc.2012.05.003.

[21] ABAQUS. (2010). User's and theory manuals version 6.10-1. RI, USA: Hibbit, Karlsson and Sorensen, Inc.

[22] American Society of Mechanical Engineering. (2013). ASME Boiler \& Pressure Vessel Code II Part A2 Materials Ferrous Material Specific.

[23] Bensari. A. (2018). Numerical Simulation of a Steel Weld Joint and Fracture Mechanics Study of a Compact Tension Specimen for Zones of Weld Joint, Fracture and Structural Integrity, 47, p 17-29, DOI: 10.3221/IGF-ESIS.47.02

[24] Shubert, M., Pandheeradi, M., Arnold, F. and Habura, C. (2010). An Abaqus Extension for Welding Simulations and Bechtel. Marine Propulsion Corporation, Providence, RI, USA. 